\title{
Panorama naval ibérico en los siglos XVI y XVII: desarrollo, innovaciones y guerra naval
}

\section{A prospect of the Iberian nautical scene in the $16^{\text {th }}$ and $17^{\text {th }}$ centuries: development, innovations and naval warfare}

\author{
DANIEL MIGUEL NIEVA SANZ \\ Universidad Autónoma de Madrid \\ daniel.nievasanz@gmail.com
}

\begin{abstract}
Resumen: Desde finales del siglo XV hasta el último tercio del XVII las naciones ibéricas ostentaron el dominio de los mares y océanos del orbe a través de un claro liderazgo en la tecnología naval. El principal objetivo de este artículo es ofrecer una aproximación general al desarrollo naval hispánico en los siglos XVI y XVII, organizándose para ello en tres bloques diferenciados. En primer lugar, una breve introducción a la navegación a inicios de la modernidad junto a los elementos humanos, científicos y técnicos que la hicieron posible. Tras este preludio, le sigue el grueso del trabajo en el que se desgranan los distintos aspectos de las armadas hispánicas del momento, procurando ofrecer al lector una visión de conjunto a partir de la cual pueda profundizar mediante los numerosos autores mencionados. Finalmente, en el último bloque se analiza su aplicación bélica desde los puntos de vista táctico y tecnológico, pues su desarrollo supuso la génesis de la guerra naval moderna tan determinante en la balanza geopolítica de los siglos subsiguientes.
\end{abstract}

Palabras clave: Navegación moderna, galeón, astilleros, barcos, artillería naval.

Abstract: The Iberian nations held control of the seas from the late $15^{\text {th }}$ century up to the second half of the 17th century through a clear leadership in nautical architectural innovations. The main target of this article is to approach the issue of the Spanish maritime technological development in the $16^{\text {th }}$ and $17^{\text {th }}$ centuries. To do so, the information is divided into three parts, starting with a brief introduction to navigation at the beginning of Modern Age together with the human, scientific and technical elements that made it possible. After this prelude, the bulk of the article examines different aspects of the Hispanic Navy, offering an overall view through the contributions of the numerous authors mentioned. Finally, an analysis of its application to naval warfare is presented from a tactical and technological perspective, since its development supposed the genesis of modern naval war and defined the geopolitical balance of the subsequent centuries.

Key words: Modern navigation, galleon, shipyards, ships, naval artillery.

Recibido: 21 de septiembre de 2018; aceptado: 22 de julio de 2019; publicado: 30 de septiembre de 2019. Revista Historia Autónoma, 15 (2019), pp. 71-91

e-ISSN: 2254-8726; DOI: https://doi.org/10.15366/rha2019.15.004 


\section{La navegación a inicios de la Edad Moderna}

A tenor de los grandes hitos de la navegación peninsular a finales del siglo xv y principios del XVI, los marinos modernos se habían desprendido del infundio medieval que estigmatizaba la navegación hacia el oeste. No obstante, los hombres que alcanzaron tales hazañas surcando las masas de agua del planeta eran conscientes de las exigencias logísticas que la navegación oceánica podía imponer, de la imprecisión de la navegación por estima y de la inexactitud del magnetismo terrestre; por consiguiente, el interés y la importancia de la ciencia aplicada a los instrumentos náuticos aumentó sustancialmente. Los primeros textos dedicados al arte de navegar aludían a la importancia de la ciencia aplicada a la navegación. Un ejemplo es la obra del cosmógrafo Don Martín Cortés de Albacar-Breve compendio de la sphera y de la arte de navegar (1551)-, donde recuerda a aquellos que en pretérito se entregaron a ella desconociendo que suerte les esperaba.

\footnotetext{
Estos beneficios (de la navegación) no fueron sin notorios peligros y con grandes atrevimientos por los que los primeros marineros sin tener piloto que los llevase, ni aguja que los encaminase, ni carta de marear por donde se rigiese, se atrevían a entrar por mares incognitos no teniendo experiencia de los vientos, ni sabiendo los puertos: ni quien los ayudase de los desastres inopinados de la navegación. ${ }^{1}$
}

Ante la ausencia total de referentes fijos era imprescindible conocer la posición de la embarcación, para lo que se recurre a la aritmética, trigonometría, geometría y astronomía, efectuando la conversión de observaciones científicas obtenidas mediante artilugios de medida como cuadrantes, ballestillas y astrolabios en información necesaria para lograr una navegación ortodrómica efectiva ${ }^{2}$. A modo de referente y soporte a las medidas tomadas in situ se utilizan tablas como las astronómicas alfonsíes, de época medieval, y, a partir de 1496, las de Abraham Zacuto. Estas, incluidas en su obra Almanach Perpetuum ${ }^{3}$, eran empleadas para conocer la declinación solar ejerciendo de herramienta imprescindible para los marinos del momento; además, se convirtieron en base teórica de adaptaciones posteriores como las de Gaspar Nicolas (1517-1520), Martin Fernández de Enciso (1529-1532) o Pedro Nunes (1537-1540)4.

Son tiempos de apasionantes innovaciones de toda índole, pues a pesar de que la orientación nocturna a través de la estrella polar ya era conocida por los marinos griegos y

\footnotetext{
${ }^{1}$ Cortés, Martín, Breve compendio de la sphera y de la arte de navegar (1551), Edición Facsímil, Editorial Maxtor, 2003.

${ }^{2}$ Maura García, Francisco de Asís, La ingeniería naval: artillería, navegación y guerra en el mar, Salamanca, Universidad de Salamanca, pp. 25-27.

${ }^{3}$ Chabás, José y Bernard R. Goldstein, Abraham Zacut (1452-1515) y la astronomía en la Península Ibérica, Salamanca, Universidad de Salamanca, 2010, pp. 107-177.

${ }^{4}$ Sellés, Manuel A., Instrumentos de navegación: del Mediterráneo al Pacífico, Barcelona, Editorial CSIC-CSIC Press, 1994, p. 51.
} 
fenicios que dominaron el piélago, la utilización del sol para la orientación diurna en alta mar aún se resistía. Será a partir de este momento cuando se controle la observación de tres referencias astronómicas esenciales: la cruz del sur, la estrella polar y el sol; lo que dio rienda suelta a una navegación astronómica más compleja ${ }^{5}$.

\subsection{Instrumentos náuticos}

En lo que respecta a la orientación, algunos siglos atrás los marinos musulmanes absorbieron de los navegantes chinos el arte de navegar con la aguja de marear o brújula náutica, extendiendo su uso en el Mediterráneo de tal manera que, en el siglo xiv, todos los hombres de mar fuera cual fuese su cultura, etnia o religión, empleaban la brújula para orientarse durante las largas travesía ${ }^{6}$. Originalmente se trataba de una simple aguja de hierro imantada flotando sobre líquido contenido en un plato o vasija, pero en respuesta a las necesidades náuticas se dotó de un eje de giro y se superpuso sobre una rosa de los vientos para que marcase rumbos ${ }^{7}$. A mediados del siglo Xvi proliferó un número importante de relojes solares y compendios astronómicos como los elaborados por Ulrich Schniep, cuya magnífica obra data de 1581 y consta de nocturlabio, reloj de sol para latitud fija, calendario lunar, brújula y rosa de los vientos ${ }^{8}$.

Otro instrumento esencial para la navegación moderna es la ballestilla, perfeccionada en el XVI por Gualteros Arsenius, uno de los más relevantes artífices de instrumentos científicos del momento y pariente del gran astrónomo y matemático holandés Gemma Frisius, quien desarrolló importantes innovaciones en el ámbito de la cartografía y la astronomía. A este artilugio también se le conocía como radio astronómico o báculo de Jacob, y era utilizado por los marinos del momento para determinar la latitud midiendo el ángulo que forma el astro con el horizonte, basándose en el mismo principio geométrico que el kamal oriental ${ }^{9}$. Está compuesto por una escala de madera sobre la cual se desliza otra menor para visar el horizonte y hacer coincidir la parte superior de la sonaja con el astro deseado ${ }^{10}$. No obstante, la imprecisión era manifiesta, pues al ser todo manual el propio vaivén de la embarcación hacía del resultado una mera aproximación ${ }^{11}$.

En lo que respecta al cuadrante, se trata de un instrumento de medida ya conocido y empleado por astrónomos medievales desde siglos atrás. Consiste en un cuarto de un círculo dividido en 90 grados de cuyo vértice sale una plomada que cuelga sobre el arco graduado,

\footnotetext{
${ }^{5}$ Maura García, Francisco de Asís, La ingeniería naval... op. cit., p. 27.

${ }^{6}$ Shamsuddín Elia, Ricardo Horacio, Civilización del Islam, Biblioteca Islámica «Fátimah Az-Zahra» Se., 2012, p. 287.

${ }^{7}$ González, Francisco José, "Del Arte de marear a la navegación astronómica: Técnicas e instrumentos de navegación en la España de la Edad Moderna”, en Cuadernos de Historia Moderna, Anejos, 5 (2006), p. 142.

${ }^{8}$ Actualmente se conserva un ejemplar en el Museo Nacional de Ciencia y Tecnología de Madrid.

${ }^{9}$ Louzán Lago, Felipe, Génesis y evolución de los instrumentos de alturas usados en navegación: análisis de los errores cometidos durante las observaciones, tesis doctoral, Universidade da Coruña, 2005, p. 349.

${ }^{10}$ Maura García, Francisco de Asís, La ingeniería naval... op. cit., p. 29.

${ }^{11}$ La ballestilla de Arsenius más antigua que se conserva es un ejemplar completo de 1563 expuesto en el Museo Nacional de Ciencia y Tecnología de Madrid.
} 
determinando la altura sobre el horizonte del astro que se observa. No obstante, en su aplicación naval se suprimió la plomada por una barra metálica que evitara, sin éxito, la imprecisión propia de las mediciones a bordo ${ }^{12}$.

[...] tomará con ambas manos su cuadrante, y ponga el ángulo superior alzando o bajando, hasta que el rayo de sol entre por el agujero de la pinula más alta, y pase a dar directamente en el agujero de la otra pinula baja. Y estando el rayo derecho por ambos agujeros, mírele donde toca el hilo de la plomada, y los grados que mostrare, aquellos se toman de cuadrante. ${ }^{13}$

El astrolabio, "una representación bidimensional de la esfera celeste capaz de reproducir, de forma manual, su movimiento de rotación diario"14, también fue utilizado por astrónomos, matemáticos y navegantes que localizaban los astros en el horizonte determinando su altura y recorrido a fin de conocer con precisión la latitud en la que se encontraban. El origen del astrolabio se sitúa en la antigüedad, pero el perfeccionamiento y aplicación generalizada de este instrumento en tiempos modernos se debe también a los musulmanes, quienes lo utilizaban para medir los horarios de oración y orientarse hacia la Meca a través del oficio denominado muwaqqit ${ }^{15}$.

Figura 1: Dibujo esquemático de un Cuadrante del siglo XvI.

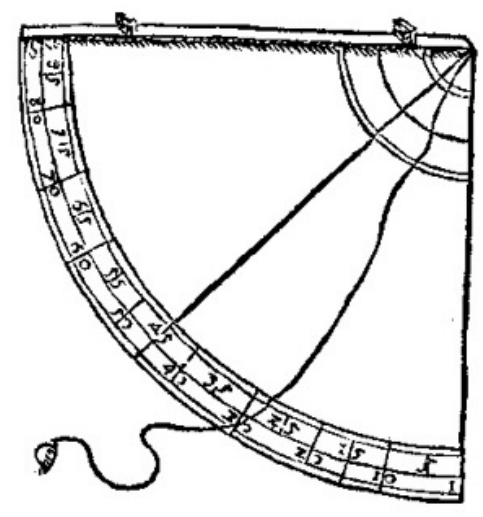

Fuente: García de Palacio, Diego, Instrucción náutica, para el buen uso y regimiento de las naos, su traça, y su gobierno conforme a la altura de México, Virreinato de Nueva España, 1587. Edición Facsímil. Valladolid, Editorial Maxtor, 2007, p. 25.

Por otra parte, el dominio de la longitud no llegaría hasta el siglo XVIII, por lo que los capitanes estimaban su posición en un mapa en base a su experiencia y la velocidad que

\footnotetext{
${ }^{12}$ González, Francisco José, "Del Arte de marear... op. cit., p. 141.

${ }^{13}$ García de Palacio, Diego, Instrucción náutica, para el buen uso y regimiento de las naos, su traça, y su gobierno conforme a la altura de México, Virreinato de Nueva España, 1587. Edición Facsímil, Valladolid, Editorial Maxtor, 2007, p. 25.

${ }^{14}$ Pérez Hernández, Azucena, “Arte y ciencia en Al-Andalus: el astrolabio nazarí de Alcalá la Real”, en Boletín del Instituto de Estudios Giennenses, 215 (2017), p. 261.

${ }^{15}$ Ibídem, p. 261.
} 
registraba su embarcación. Para ello, utilizaban la corredera de barquilla creada en 1577 a fin de determinar a cuantos nudos iba la nave y cuanta distancia se había recorrido ${ }^{16}$. Se trata de una pieza de madera que se arroja por popa atada a un cordel con nudos a iguales intervalos $\mathrm{y}$, a través del conteo de nudos en un determinado lapso mediante una ampolleta o un reloj de arena, se estima la distancia recorrida por la embarcación ${ }^{17}$.

Por último, cabe destacar la inestimable aportación de la cartografía, cuyo desarrollo estuvo fuertemente vinculado a las innovaciones náuticas del momento. En este sentido, es preciso mencionar la "carta de marear" 18 de Juan de la Cosa (1500); la primera representación cartográfica del nuevo mundo que supera la visión mitográfica precedente, y preludio de la transición entre la tradición medieval de los portulanos y la cartografía moderna. Para la escuela de Sevilla la elaboración de las cartas náuticas se convirtió en una labor cada vez más rigurosa y menos imaginativa, pues estas constituyeron uno de los instrumentos vitales para una navegación segura y efectiva ${ }^{19}$.

En definitiva, el navegante de la época debía ser ducho en el manejo de instrumentos astronómicos, pues así lo exigía su condición y esperanza de éxito. Esto queda reflejado por Don Diego García de Palacio refiriéndose a las cualidades ideales que debían tener los marineros, del primero al último: “[...] echar punto en una carta, tomar la altura con el cuadrante, astrolabio y ballestilla, arrumbar las guardas del norte, por cada cuarta, para las horas de la noche, y por ellas saber dónde está el sol y la luna"20.

\section{Armadas hispánicas en los siglos XVI y XVII}

La relativa estabilidad socioeconómica disfrutada por el Reino de Portugal en la segunda mitad del siglo xv le permitió liderar la vanguardia de los avances técnicos aplicados a la navegación, de modo que tomó una posición ventajosa en el dominio de las rutas atlánticas que contorneaban África y que constituían la única vía segura a oriente tras la caída de Constantinopla en 1453. No obstante, las transformaciones navales redundarían en todos los marinos ibéricos a comienzos de la siguiente centuria, pues los castellanos, ávidos de exploración e impulsados por la gesta náutica de Cristóbal Colón, darían un paso sin precedentes en la expansión oceánica y el dominio del orbe.

\footnotetext{
${ }^{16}$ Maura García, Francisco de Asís, La ingeniería naval... op cit., p. 30.

${ }^{17}$ González, Francisco José, Astronomía y navegación en España. Siglos XVI-XVIII, Madrid, Mapfre, 1992, pp. 63-64.

${ }^{18}$ Original conservado en el Museo Naval de Madrid.

${ }^{19}$ Martín-Merás Verdejo, Luisa, "La carta de Juan de la Cosa: interpretación e historia", en Monte Buciero, 4 (2000), p. 72.

${ }^{20}$ García de Palacio, Diego, Instrucción náutica... op. cit., p. 119.
} 
Las flotas lusas y castellanas de principios del siglo XVI eran de esencia compleja y muy heterogénea. No fue hasta el reinado de Carlos I cuando comienza una clara preocupación por consolidar la hegemonía naval hispánica sobre el resto de las potencias europeas, somnolientas aún en lo que a navegación moderna se refiere. Buscó la dinamización del sector innovando y perfeccionando las calidades y cualidades de las nuevas naves, incrementando su versatilidad en los mares del globo. Esta predilección del monarca por el desarrollo naval fue transmitida a su hijo Felipe II que, ante la necesidad de nuevos barcos más veloces y capaces de transportar mayor tonelaje en las rutas a las indias, impulsó el desarrollo de la industria naval española hasta su cenit. Se crearon nuevos cuadros de mando encargados de armadas más sofisticadas como las de "los doce galeones de la Guarda de la Carrera", "la Armada de Barlovento en La Habana" y "la Armada del Mar del Sur en Perú"21. "Los castellanos pretenden hacer naos grandes y pequeñas, y de todas suertes, modos y maneras, para navegar con ellas todo el mar del mundo, y que sirvan de todas las cosas juntas a que sirven todas las de todos (los demás) reinos" ${ }^{22}$.

Sin duda, durante el siglo XVI el liderazgo ibérico en la expansión ultramarina fue incontestable, pero, a finales de siglo, la proto-ingeniería náutica entró en un ambiente de férrea competencia entre todas las potencias europeas. En 1598 la corona convocó un concurso internacional con objeto de hallar un método seguro y eficaz para determinar la longitud geográfica en la mar, entregando al ganador una suculenta cantidad de dinero como compensación. Al poco tiempo, Holanda, cuyo potencial marítimo crecía aceleradamente, sería quien convocara otro concurso de idénticas condiciones, evidenciando la frenética pugna que se estaba desembocando ${ }^{23}$. Se trata de un momento en el que intelectuales, ingenieros y marinos de toda Europa debatían a lo largo y ancho del continente acerca de las mejoras aplicables en los nuevos buques que dominarían los océanos: su manga y eslora ideal, su capacidad de carga, la incorporación de más cañones sin hacer zozobrar la embarcación o la posibilidad de alcanzar mayores velocidades, entre otras muchas preocupaciones náuticas ${ }^{24}$.

La primera mitad del siglo XVII estuvo marcada por un intento español de resistir como potencia naval hegemónica a través de la homogenización de la construcción naval. Así lo reflejan las sucesivas ordenanzas elaboradas a tal efecto durante el primer tercio de centuria y la construcción de escuadras provinciales que conformarían la Armada del Mar Océano, cuya acción más notable fue la expulsión en 1625 de barcos holandeses de la bahía de todos los

\footnotetext{
${ }^{21}$ Casado Soto, José Luis, Los barcos españoles del siglo XVI y la Gran Armada, Madrid, Instituto de Historia y Cultura Naval, 1988, pp. 136-139.

${ }^{22}$ Escalante de Mendoza, Juan, Itinerario de las tierras y mares occidentales, 1575.

${ }^{23}$ González, Francisco José, "Cinco siglos circunnavegando el planeta", en Boletín de la Institución Libre de Enseñanza, 87 (2012), pp. 37-38.

${ }^{24}$ Ibídem, pp. 37-38.
} 
santos (Brasil) ${ }^{25}$ mediante una colaboración entre castellanos y portugueses que reafirmó la unión de $\operatorname{armas}^{26}$.

La Monarquía de España consta de reinos tan separados que necesita fuerzas superiores en el mar para oponerse a las fuerzas de los reyes, potentados y provincias que envidian su grandeza y su riqueza y desean su destrucción. [...] Es, por lo tanto, deseable que Vuestra Majestad ordene que en todo momento haya una cantidad de barcos de la calidad, tamaño y fuerza requeridos, y no solo para las armadas [...] sino también para la industria y el comercio y demás propósitos necesarios. ${ }^{27}$

La reputación y la solvencia de la monarquía hispánica pasaba por ostentar un poder naval férreo que no dejara duda de su capacidad ${ }^{28}$. Esa voluntad y determinación que se requería para establecer una estrategia naviera eficiente había llegado a través de la decidida política naval del Conde Duque de Olivares que, con la creación de la Junta de Armadas en $1622^{29}$ y el incremento de la construcción naval, logró el mantenimiento del liderazgo español en los mares y océanos del globo pese a la boyante incorporación francesa dirigida por su homólogo el cardenal Richelieu ${ }^{30}$. Sin embargo, para la segunda mitad de la centuria decimoséptima, la primera línea del poder naval se encontraba ya en un aparente equilibrio de pesos y contrapesos entre Inglaterra, Francia y Holanda, mientras que Portugal, a pesar de la emancipación de 1640, no gozaba de un presente ideal, compartiendo la misma necesidad que España en lo que respecta al sostenimiento de las rutas con sus lejanas posesiones.

\footnotetext{
Las escoltadas a las flotas de Indias, y el llamado galeón de Manila, las armadas de Barlovento y del Sur, en ambos flancos de América, y la del Mar Océano en Europa, sostuvieron la presencia hispana en los océanos; mientras en el Mediterráneo, además de los galeones cuando fuese necesario, las escuadras de galeras de Nápoles, Sicilia, Génova y España resultaron suficientemente capaces como para mantener las comunicaciones entre los diversos reinos hispanos separados por el mar interior, e incluso para perturbar seriamente los planes franceses durante la última década de la centuria. ${ }^{31}$
}

\footnotetext{
${ }^{25}$ Casado Soto, José Luis. "Barcos para la guerra. Soporte de la Monarquía Hispánica”, en Cuadernos de Historia Moderna, 5 (2006), pp. 35-37.

${ }^{26}$ Remartínez Martínez, Carlos, "Las armadas de Felipe IV: La conservación de la monarquía", en Revista Historia Autónoma, 13 (2018), p. 82. Doi: https://doi.org/10.15366/rha2018.13.004

${ }^{27}$ Goodman, David y Juan Pedro Campos, El Poderío naval español: historia de la armada española del siglo XVII, Barcelona, Península, 2001, p. 31.

${ }^{28}$ Remartínez Martínez, Carlos, "Las armadas de Felipe IV... op. cit., p. 78.

${ }^{29}$ Rivero Rodríguez, Manuel, La monarquía de los Austrias. Historia del Imperio español, Madrid, Alianza Editorial, 2017, pp. 230-231.

${ }^{30}$ Casado Soto, José Luis, "Barcos para la guerra... op. cit., p. 36.

${ }^{31}$ Ibidem, p. 37.
} 


\subsection{Construcción naval e innovaciones}

A lo largo del siglo XVI la construcción de naves no era aún sistemática, sino que se trataba de un proceso singular y considerablemente desordenado. Sin embargo, este señero proceso envolvía a la nave, a su construcción y a su botadura en una simbólica esfera de exclusividad que generaba un fuerte sentido de pertenencia en toda la tripulación. Sorprende lo reflexivo de las descripciones de una nao y todo lo que conlleva por parte de Don Diego García de Palacio, marino y escritor del primer manual del arte náutico editado en el mundo (1587), "Instrucción náutica, para el buen uso y regimiento de las naos, su traça, y su gobierno conforme a la altura de México", quien comienza su libro cuarto con una analogía entre el hombre y la nave varios siglos antes de la "metáfora orgánica” teorizada por sociólogos del siglo XIX:

\footnotetext{
Y pues el navío, con todo lo que en el debe haber de personas y aderezos, se puede comparar a una republica concertada y ordenada, lo vaya figurando por ella o por el sujeto de un hombre: pues en él hay anima y cuerpo, y potencias aplicadas para todas las obras necesarias a su conservación: y tiene acciones y movimientos necesarios a sus fines, y ordenadas a las vegetativas y a las sensitivas, y estas a las intelectuales... lo material es como el cuerpo, los maderos como los huesos, la jarcia y cuerdas como los nervios; las velas, como muchos pañizuelos y rendones que hay en escotillón: como boca, tiene también vientre y otros lugares para purgarle y limpiarle como los tiene el hombre. ${ }^{32}$
}

Al margen del carácter simbólico y social, el historiador José Luis Casado Soto ${ }^{33}$ describe a la perfección el esquema estructural de los barcos del momento siguiendo el eje formado por la quilla, el codaste y el branque. Toda esta estructura interna estaba cubierta por un armazón de cuadernas perpendiculares al eje y paralelas entre sí, clausuradas en la parte superior por los denominados baos que forrados por las tracas longitudinales formaban la cubierta. Sobre toda esta estructura se alzaban las vergas y el velamen encargados de transmitir la fuerza del viento transformándola en impulso para la nave.

Desde el siglo XVI se venían aplicando innovaciones relevantes en los barcos españoles: se crearon nuevos betunes y pinturas para cubrir la obra viva o carena, forrándolas con plomo en caso de travesías largas, y se inventaron nuevas bombas de achique. De todos los elementos que componen la morfología de una embarcación, el casco es el más importante y fundamental para el resto. Este se divide en la obra muerta, la parte que sobresale por encima de la línea de flotación, y la obra viva, la más importante para la integridad e hidrodinámica de la nave. Dar forma a la obra viva ha sido el rompecabezas de los constructores de barcos de todos los tiempos, pues no existía aún un método matemático claro, siendo aún difícil su estudio en la actualidad puesto que la mayoría de las representaciones de la época muestran embarcaciones sobre la

\footnotetext{
${ }^{32}$ García de Palacio, Diego, Instrucción náutica... op. cit., p. 89.

${ }^{33}$ Casado Soto, José Luis, "Barcos para la guerra... op. cit., pp. 15-53.
} 
mar donde la obra viva no es visible al estar sumergida por debajo de la línea de flotación ${ }^{34}$. Esta problemática persiste a finales del siglo XVII, pues en el "Théorie de la Construction des vaiseaux" (1697), se hace referencia precisamente a la suerte que en ocasiones determina el éxito de una nave:

La suerte tiene tanto que ver con la construcción que los navíos que se construyen con más cuidado son con frecuencia los peores; y los que se fabrican sin cuidado, son a veces los mejores. Así, los navíos más grandes son a menudo los más defectuosos; y se ven buques mejores entre los mercantes que en la marina real. ${ }^{35}$

Figura 2: Planos de barcos de guerra incluidos en el tratado de Garrote (1691).
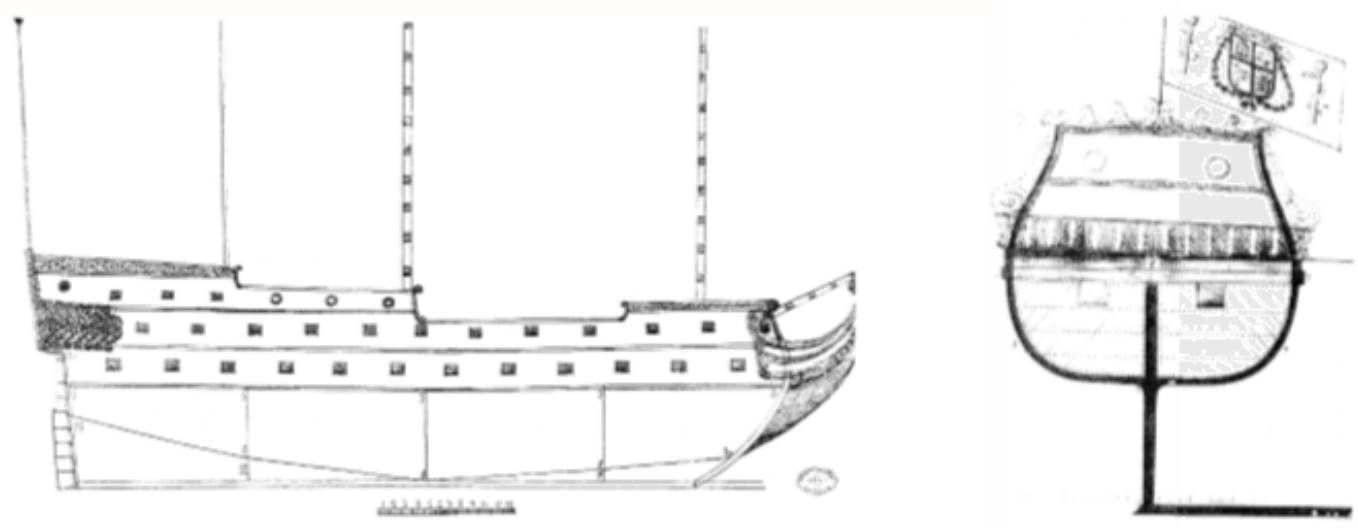

Fuente: Archivo General de Indias, Sevilla ${ }^{36}$.

La madera fue el material esencial en la construcción naval de las centurias que nos ocupan, siendo los elaborados en el cantábrico generalmente de roble, mientras que los barcos criollos construidos en las Indias empleaban maderas exóticas como el guachapelí, palo de maría, canelo, mangle y laurel. En lo que respecta al ancla, la clavazón y los accesorios metálicos se empleaba hierro peninsular en ambos casos, de igual manera que la brea y el alquitrán. Para el calafateado se optaba por estopa de cáñamo en las embarcaciones de construcción cántabra y fibra de coco seco en las criollas, estas últimas empleando para el velamen lonas de Nicaragua, Perú y Filipinas ${ }^{37}$.

\footnotetext{
${ }^{34}$ Ibidem, p.36.

${ }^{35}$ Hoste, Paul, Théorie de la Construction des vaiseaux, 1697. Cit. por González, Francisco Fernández, “Arqueología de la Arquitectura Naval", en Vicente Vázquez, Ramón de (ed.), Cátedra Jorge Juan: ciclo de conferencias: Ferrol, curso 1994-1995, A Coruña, Universidad de A Coruña, 1996, p.186.

${ }^{36}$ Extraído de: Casado Soto, Casado Soto, "La construcción naval hispana en época moderna", en Cau Ontiveros, Miguel Ángel y Francisco Xavier Nieto Prieto (eds.), Arqueología náutica mediterránea, Girona, Museu Arqueologia de Catalunya y Centre d'Arqueologia Subaquàtica de Catalunya, 2009, p. 403.

${ }^{37}$ González Fernández, Marcelino, "Los barcos españoles en el Pacífico. Siglos XVI a XVIII", Montero Llácer, Francisco Javier (ed.), El océano pacífico: conmemorando 500 años de su descubrimiento, Madrid, Fundación
} 
A lo largo de los siglos XVI y XVII, la madera para la construcción naval generó un constante desasosiego en los monarcas españoles. Felipe II manifestó con claridad su preocupación por la conservación de los bosques, pues de ellos dependía el aprovisionamiento de los astilleros del Imperio que nutrían de naves a las armadas encargadas de su defensa: "una cosa deseo ver acabada -le indicó a un ministro en 1582- y es lo que toca a la conservación de los montes [...]. Temo que los que viniesen después de nosotros han de tener mucha queja de que los dejamos consumidos, y plegue a Dios que no lo veamos en nuestros días"38.

Tras la unión de coronas en 1580, Felipe II pasó a controlar las "coutadas y matas" o reservas forestales que formaban parte del patrimonio del Rey de Portugal, lo que generó una importante controversia ya que en los años previos a la unión ya existía una creciente preocupación por la incapacidad de satisfacer las necesidades navales portuguesas, ergo ahora que de ellas podrían beneficiarse las armadas castellanas atendiendo a los intereses del monarca la tensión aumentó considerablemente ${ }^{39}$.

No obstante, no se desarrolló una política eficaz de protección forestal hasta la llegada al trono de Felipe III quien, preocupado por la situación naval del Imperio, designó a Diego Brochero de Anaya encargado para su recuperación ${ }^{40}$. El 30 de enero de 1607 se creó en Madrid una Junta de maestros con intención de reunir a los mejores constructores de navales del momento y definir algunas estandarizaciones de los buques que debían construirse en España y Portugal ${ }^{41}$. Se dejaba atrás la construcción singular donde cada nave era una obra única de un maestro constructor, con los problemas logísticos que ello suponía para la reparación o el almacenaje $\mathrm{y}$, por tanto, se daban los primeros pasos hacia una construcción estandarizada y en cadena, si bien aún muy lejos del ideal de producción naval para un imperio de sus características. Los trabajos de John Wing ${ }^{42}$ revelan de qué manera la madera se convirtió en un agente político con influencia directa en la formación de los estados modernos y la articulación de su territorio, pues suponía un elemento de vital importancia para el mantenimiento de estos ${ }^{43}$.

Un alto porcentaje de los buques empleados por la monarquía hispánica a comienzos del siglo XVII provenían de los astilleros de las costas cántabras y vascas, siendo destinados a la carrera de Indias, a la Armada del Mar Océano o al Mediterráneo. En cambio, para la segunda mitad de siglo las flotas de Indias se nutrían ya de un $50 \%$ de barcos extranjeros y otro tanto de naturales, dentro de estos últimos un $20 \%$ se trataba de barcos $\operatorname{criollos}^{44}$. No

\footnotetext{
Ramón Areces, 2014, p. 93.

${ }^{38}$ Cit. por Kamen, Henry, Felipe de España, Barcelona, Siglo XXI, 1998, p. 192.

${ }^{39}$ Monchet, Koldo Trápaga, "Las armadas en el reino de Portugal en los reinados de los Felipes (1580-1640)", en García Fernández, Máximo (ed.), Familia, cultura material y formas de poder en la España moderna: III Encuentro de Jóvenes Investigadores en Historia Moderna, Valladolid, Universidad de Valladolid, 2016, pp. 843854.

${ }^{40}$ Melero Guillo, María Jesús, A la Mar Madera: La madera en la arquitectura naval española, Actas de la IX Jornada de Andalucía y América, Sevilla, Universidad Internacional de Andalucía, 1991, pp. 147.

${ }^{41}$ Ibídem.

${ }^{42}$ Wing, John T, Roots of empire: State formation and the politics of timber Access in early modern Spain, 15561759, tesis doctoral, University of Minnesota, 2009.

${ }^{43}$ Monchet, Koldo Trápaga, "Las armadas en el reino ... op. cit., p. 844.

${ }^{44}$ Casado Soto, José Luis, "Barcos para la guerra... op. cit., p. 43.
} 
obstante, se siguió prefiriendo los astilleros cántabros, como el de Colindres, pues construían embarcaciones más caras pero superiores en cuanto a fortaleza y seguridad que las extranjeras de similares dimensiones ${ }^{45}$. Esta preferencia por los astilleros peninsulares se mantiene hasta finales del siglo XVII, siendo alabados en el tratado de Garrote en 1691: "El cuidado que han puesto los españoles en sus baxeles es en la fortaleza de maderas, clavazón y pernería, en que confieso exceden a todas las naciones" ${ }^{\prime 46}$.

Además, cabe una mención al noroeste peninsular, ya que al final de la centuria precedente también tuvieron lugar importantes modificaciones de las infraestructuras navales y la organización de la costa, pues tras las constantes razias de corsarios como el ataque del conocido Francis Drake a la Coruña en 1589, la corona asumió la relevancia geoestratégica de las costas gallegas en el marco de la hostilidad con Inglaterra ${ }^{47}$. Se establecieron hornos, lonjas y todo tipo de servicios destinados al apoyo en tareas de avituallamiento de naves, se construyeron los astilleros de la Graña y se concentró la actividad naval del puerto de Ferrol, sentando las bases de lo que será su evolución hacia el imponente Arsenal del siglo XVIII. Sin embargo, a pesar de los proyectos mencionados, con el cambio de monarca la región volvió a ocupar un papel relativamente secundario ${ }^{48}$.

En las costas de la actual Guipúzcoa también se elaboraban una gran cantidad de naves de alta calidad diversificando la producción a fin de mantener una actividad constante y heterogénea. A comienzos del siglo XVII, las atarazanas de Pasajes y la rivera del Oria se especializaron en la construcción de naves de gran tamaño para las armadas y flotas reales botando a lo largo del siglo numerosos Naos, Galeones y Navíos de línea, aunque también funcionaban otros astilleros destacables en la zona como los de Irún, Fuenterrabía, Zarauz y San Sebastián ${ }^{49}$.

Afinales de la centuria decimoséptima, los astilleros españoles en las Américas comenzaron a ganar protagonismo debido a los intentos desesperados por mantener el control del Atlántico. Destacó especialmente el astillero de la Habana, de tal suerte que en el siglo XVIII ocuparía un papel esencial junto al peninsular de Guarnizo y los arsenales de Ferrol, Cádiz y Cartagena en la recuperación naval de época borbónica ${ }^{50}$.

\subsection{Tipologías navales de la Monarquía Hispánica}

Es importante señalar la confusión existente con respecto a los distintos tipos de naves empleadas en esta época debido a las modificaciones permanentes que incorporaban mejoras,

\footnotetext{
${ }^{45}$ Ibidem, p. 37.

${ }^{46}$ Cit. por Casado Soto, José Luis, "Barcos para la guerra... op. cit., p. 37.

${ }^{47}$ Saavedra Vázquez, María del Carmen, "Política naval, corsarios y armadas en la Galicia moderna", en Minius: Revista do Departamento de Historia, Arte e Xeografía, 21 (2013), pp. 99-101.

${ }^{48}$ Ibidem, p. 60.

${ }^{49}$ Odriozola, Lourdes, "La construcción naval en Gipuzkoa. Siglos XVI-XVIII”, en Itsas Memoria, Revista de Estudios Maritimos de País Vasco, 2 (1998), pp. 93-96.

${ }^{50}$ Kuethe, Allan J. y José Manuel Serrano Alvarez, "El astillero de la Habana y Trafalgar", en Revista de Indias, vol. 67, 241 (2007), pp. 763-776. https://doi.org/10.3989/revindias.2007.i241.630
} 
elementos provenientes de la copia de naves capturadas ${ }^{51} \mathrm{o}$ informaciones obtenidas a través del espionaje tecnológico, además de la errada nomenclatura devenida de las transcripciones imprecisas de escribanos terrestres que empleaban términos genéricos indistintamente o dos denominaciones para la misma embarcación ${ }^{52}$. Por ende, la relación que se expone a continuación no tiene mayor pretensión que la de una mera aproximación al complejo crisol náutico del momento, entendiendo que su desarrollo no fue unilineal, sino que estuvo caracterizado por una heterogeneidad tal como la propia del imperio en el que aconteció.

En primer lugar, cabría mencionar el Bergantín, un barco de reducido tamaño con unos 13 metros de eslora y 10-15 remeros por banda, siendo uno de los primeros empleados en la exploración del océano Pacífico. Habitualmente contaba con dos palos; vela cuadra en el mayor y latina en la mesana, y era conocido como "cuarto de galera", pues era rápido y de maniobrabilidad fácil, aunque poco seguro en malas condiciones de $\operatorname{mar}^{53}$.

La Nao fue el barco mercante más empleado entre los siglos XVI y XVII utilizándose también para las misiones de exploración en el Pacifico, pues era una versión mejorada de las cocas medievales o las panzudas carracas italianas de carga con capacidad para 200 toneladas. Contaba con una popa redonda, bordas altas, castillo de popa y timón de codaste. Muy característica por su mucha manga en una relación 3 con respecto a la eslora, inicialmente seguía la regla de construcción de "as, dos, tres" - as o uno para la manga, dos para la quilla y tres para la eslora“54. Estaba dotada con un aparejo de cuatro mástiles con velamen combinado, a proa con velas cuadradas y latinas aparejadas en los palos de popa. Empezó a entrar en desuso a comienzos del siglo XVII, pues desde la segunda mitad de la centuria decimosexta se venía produciendo una evolución conceptual hacia la que se convertiría en la nave hispánica por excelencia: el Galeón. Figura 3: Nao "de pozo" 1575, según Juan Escalante de Mendoza.

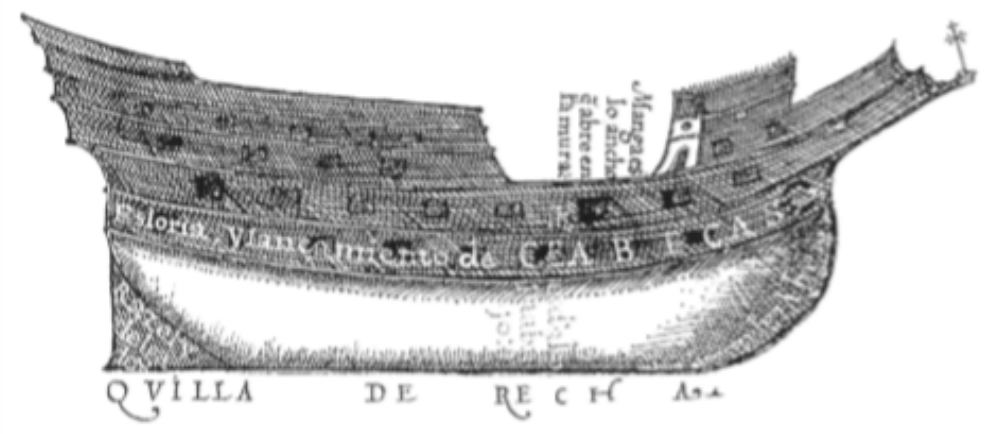

Fuente: Museo Naval de Madrid ${ }^{55}$

\footnotetext{
${ }^{51}$ Casado Soto, "La construcción naval... op. cit., p. 405.

${ }^{52}$ Casado Soto, José Luis, "Aproximación a la tipología naval cantábrica en la primera mitad del siglo XVI", en Itsas memoria, 2 (1998), pp. 171-172.

${ }^{53}$ González Fernández, Marcelino, “Los barcos españoles... op. cit., pp. 87-89.

${ }^{54}$ Ibídem, p. 89.

${ }^{55}$ Extraído de Casado Soto, José Luis, "Barcos para la guerra... op. cit., p. 34.
} 
Las galeras - circunscritas fundamentalmente al ámbito mediterráneo junto a sus variantes de menor porte galeota, galeaza, fusta y saetía ${ }^{56}$ - son herederas del concepto de embarcación de combate medieval y están dotadas de un espolón de proa para embestir en los abordajes. Alcanzan su cenit en el siglo XVI, pero su morfología y sistema de propulsión, principalmente a remo, las hacía ineficaces ante las nuevas necesidades del combate naval moderno y el evidente cambio de escenario hacia el Atlántico. Por tanto, su relevancia en el total de la producción y su uso en los menesteres del imperio decayó considerablemente siendo relegadas a algunos cometidos mediterráneos y al control de rutas fluviales ${ }^{57}$.

Desde la segunda mitad del siglo XVI el galeón coparía progresivamente el protagonismo naval como principal barco de combate, versátil y fiable: "Los galeones han de ser fabricados con mucha fortaleza, ... han de ser veleros, ... han de ser anchos ... y tener poco puntal" ${ }^{\prime 8}$. E1 galeón supone la evolución de la nao aumentando su porte, eslora y capacidad de carga, y los constructores, sabedores del papel que este desempeñaría, elevaron más la popa a fin de evitar abordajes 59 . "Prolongó el beque o pico de proa, que recordaba el espolón de la galera, alzó el castillo de popa y adquirió mucho arrufo"60.

Efectivamente, el galeón surge como resultado de estas mejoras arquitectónicas incorporando al formato nao algunos elementos de la galera, pero manteniendo el mismo aparejo de cuatro palos y la combinación de velas cuadradas y latinas. "Era muy versátil, en ocasiones bien armado, grande, de altas bordas, con una relación eslora/manga de 3,5, y un arqueo de unas 300 toneladas que fue aumentando hasta las 500"61.

Figura 4: Planos del galeón de Gregorio Sarmiento de Valladares, 1589.
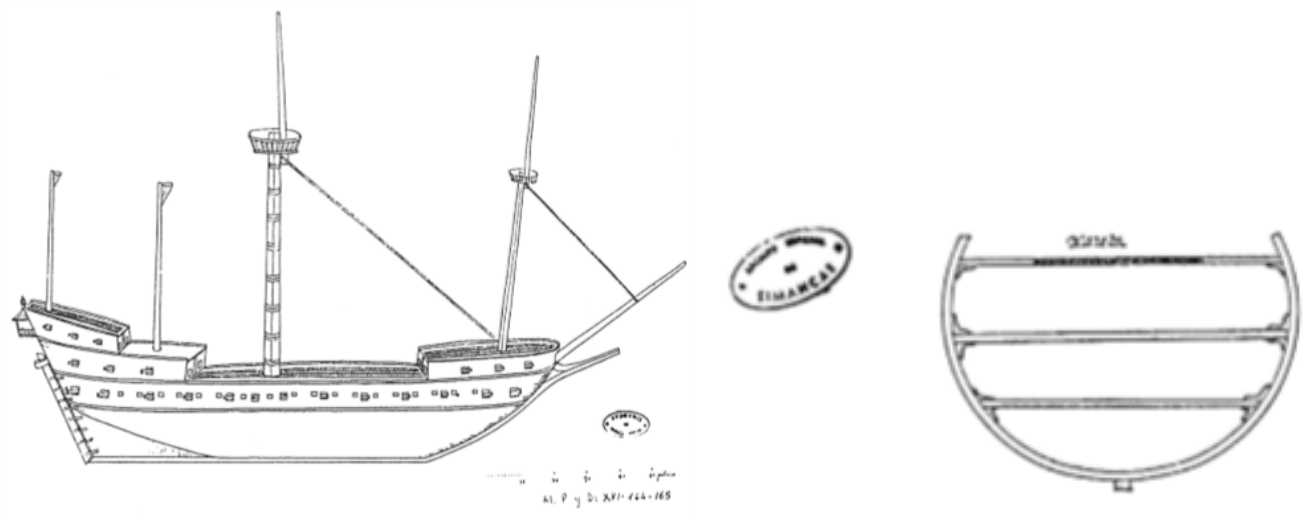

Fuente: Archivo general de Simancas, Valladolid ${ }^{62}$.

\footnotetext{
${ }_{56}$ Pi Corrales, Magdalena de Pazzis, "La armada de los Austrias", en Estudis. Revista de Historia Moderna, 27 (2001), pp. 25-26.

${ }^{57}$ Ibídem, p. 26.

${ }^{58}$ Cristóbal de Barros en las juntas de Santander y de Sevilla convocadas por Felipe II en 1581. cit. por Fernández González, Francisco, “Arqueología de la Arquitectura ... op. cit., p. 204.

${ }^{59}$ Pi Corrales, Magdalena de Pazzis, "La armada de los... op . cit., p. 28.

${ }^{60}$ González Fernández, Marcelino, "Los barcos españoles... op. cit., p. 89.

${ }^{61}$ Ibídem, p. 89.

${ }^{62}$ Extraído de: Casado Soto, José Luis, “Barcos para la guerra... op. cit., p. 38.
} 
La evolución arquitectónica del Galeón continuó ganando fuerza y capacidad ofensiva dando como resultado el Navío. En estos momentos el aparejo alcanzó un punto de homogenización estándar con tres palos: trinquete, mayor y cangreja en la mesana ${ }^{63}$. "Aumentó el armamento, desapareció el beque, ensanchó la popa que adquirió balconadas, desapareció el castillo de proa y el castillo de popa redujo su altura" ${ }^{64}$.

En la segunda mitad del siglo XVII aparecieron nuevas o se rediseñaron múltiples tipologías que complementaban las flotas del momento. No obstante, es preciso recordar que la evolución naval hispánica no se produjo de manera homogénea ni unilineal, sino que fue compleja y poliédrica dando lugar a la coexistencia de los tipos mencionados en el mismo espacio temporal, así como innumerables variantes morfológicas que conformaron un crisol náutico sin precedentes.

\subsection{Dotación y vida a bordo}

La creciente hostilidad contra las naves de la monarquía hispánica obligó a tomar medidas contundentes para garantizar la defensa de sus costas y rutas ${ }^{65}$. Por ello, desde 1537 Carlos I incorporó las compañías viejas del mar de Nápoles a las escuadras de galeras del Mediterráneo, modelo que se extendería dando lugar a la primera infantería de marina de la historia.

\footnotetext{
Estos mosquetes y arcabuces han de estar bien tratados, apuntados y con todos sus aparejos; han de tirar a los enemigos por las saeteras y procurar que el tiro sea cierto; descargando, tornara a cargar con la mayor diligencia que pudiere, para tornar a la saetera y puntería. ${ }^{66}$
}

Existen tempranas alusiones a la división terminológica entre la tripulación de mar y de guerra: "Armados los soldados, y gente de mar, es necesario que el piloto se encargue de las escotas y aparejos a marineros particulares [... $]^{\prime 67}$. Sin embargo, no es hasta la junta de guerra de 1629 cuando queda regulado que la dotación de un galeón español se divida entre gente de mar y gente de guerra, fijando su uniformidad en las ordenanzas del buen gobierno de la Armada del Mar Océano del 24 de enero de 1633. Los infantes embarcados se adaptaron a las nuevas condiciones y sustituyeron a la "gente de pelea" que sin formación específica venían desempeñando el papel ofensivo o defensivo en los abordajes hasta mediados del siglo $\mathrm{XVI}^{68}$. Estos primeros infantes estaban armados con picas, medias-picas, mosquetes y arcabuces,

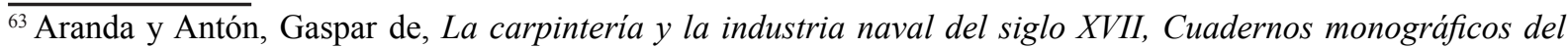
instituto de historia naval, 33 (1999), p. 9.

${ }^{64}$ González Fernández, Marcelino, "Los barcos españoles... op. cit., p. 90.

${ }^{65}$ Pi Corrales, Magdalena de Pazzis, "Los tercios en el mar", en Cuadernos Historia Moderna, 5 (2006), p. 102.

${ }^{66}$ García de Palacio, Diego, Instrucción náutica ... op. cit., pp. 123-124.

${ }^{67}$ Ibídem, p. 123.

${ }^{68}$ Pi Corrales, Magdalena de Pazzis, “Los tercios en... op. cit., p. 104.
} 
y se distribuían por compañías de distintas "naciones", generalmente españoles, italianos e irlandeses, pero todas con la misma estructura organizativa que los tercios hispánicos ${ }^{69}$.

En lo que respecta a la gente de mar, se combinaba el mando de la oficialía con la experiencia de marineros y la inquietud de grumetes y pajes. Estos tripulantes de bajo rango escaseaban muy a menudo debido a las precarias condiciones de su servicio ${ }^{70}$, lo que no impedía que todos establecieran una fuerte vinculación con la nave, ya que su sino quedaba inevitablemente ligado a ella.

\footnotetext{
"[...] de ser el hombre buen cristiano y temeroso de Dios, necesario lo es al Capitán de la nao serlo y mostrarlo, pues que de ordinario anda arriesgando la vida y siendo como ha de ser, tal conviene que sea sagaz y discreto, para tratar la diversidad de hombres que trae consigo, como convenga mostrándoseles honesto y buen ejemplo, piadoso y afable, y en reprimir los excesos riguroso $[\ldots] .^{71}$

[...] los cuales (los marineros), han de ser hombres de vergüenza, y que tengan algún caudal, y que hayan navegado y sean buenos timoneros [...], y que sean diestros en hacer y guarnecer cualquier jarcia y velas, arrumar el estiva, mandar en el batel, fajar un cable proa [...]. Han de llevar grumetes las naos, dos tercios de los marineros que son menester, por manera que llevando treinta marineros han de llevar veinte grumetes. ${ }^{72}$
}

La alimentación de soldados y marineros consistía en bizcocho (pasta de harina de trigo fermentada y cocida); agua, vino o sidra; tocino, cecina, sardinas, bacalao (salazones secados al aire); arroz, habas, garbanzos, aceite de oliva y vinagre (en barriles); verduras frescas, ajos, cebollas, alcaparras (en jarras); pollos y huevos (en corrales de cubierta); pasas y almendras ${ }^{73}$. De todo ello se encargaba el despensero: "conviene que sea hombre cuerdo, sufrido y callado, y templado en comer y beber, y que sepa escribir para asentar y tener la razón y cuento de lo que se le encargue..."74. Los espacios para la carga y la zona de habitabilidad se difuminaban en ocasiones, pues se ocupaban las diferentes estancias de la nave mediante un prolijo aprovechamiento del espacio.

La alerta se mantenía a través de un sistema de guardias, que cumplían tanto marineros como oficiales, divididas en tres turnos: la guardia del capitán, la guardia del piloto y la guardia del maestre. El grumete era el encargado de cantar la hora volteando el reloj de arena, tocando campana y recitando un verso:

\footnotetext{
${ }^{69}$ Mesa Gallego, Eduardo de, "Soldados de 'naciones' para la armada del mar océano: las compañías irlandesas de los Tercios embarcados, 1604-1639”, en Obradoiro de Historia Moderna, 24 (2015), p. 264.

${ }^{70}$ Caballos, Esteban Mira, Las Armadas Imperiales: La Guerra en El Mar en Tiempos de Carlos V y Felipe II, Madrid, La esfera de los libros, 2005, pp. 40-43.

${ }^{71}$ García de Palacio, Diego, Instrucción náutica ... op. cit., pp. 111-112.

${ }^{72}$ Ibídem, pp. 119-120.

${ }^{73}$ Sidoli, Osvaldo.,"La carrera de Indias: Los galeones”. Histamar. Historia y Arqueología Marítima, 2007. «http:// www.histarmar.com.ar/InfGral/AASidoli/CarreraIndias»» [Consultado 22 de mayo de 2018].

${ }^{74}$ García de Palacio, Diego, Instrucción náutica ... op. cit., pp. 115-116.
} 
Una va de pasada, y en dos muele; más molerá si mi Dios Querrá; a mi Dios pidamos que buen viaje hagamos; y a la que es Madre de Dios y abogada nuestra, que nos libre de agua, de bombas y tormentas. [...] ;Ah de proa! ¡Alerta y vigilante! ${ }^{75}$

El inicio del día lo marcaba la oración de mañana cantada por un paje: "Bendita sea la luz, y la santa Veracruz, y el Señor de la verdad, y la Santa Trinidad. Bendita sea el alma, y el Señor que nos la manda, bendito sea el día, y el Señor que nos lo envía"76. Continuaba un rezo de toda la tripulación finalizado con un saludo: “Amén. Dios nos dé buenos días, buen viaje, buen pasaje haga la nao, señor capitán y maestre y buena compañía, amén; así faza un buen viaje, faza; muy buenos días dé Dios a vuestras mercedes, señores de proa y popa"77.

\section{Primeros pasos de la guerra naval moderna}

Las tácticas de guerra naval eran muchas e inexistentes al mismo tiempo, puesto que la dificultad de comunicación entre navíos en combate, junto a las adversas condiciones de la mar, dejaba poco margen a la virtud militar. Incluso más de un siglo después el afamado almirante inglés Horatio Nelson abarcó en una breve exclamación la táctica naval más empleada del momento: "Simplemente, ¡A por ellos!"78. Sin lugar a duda, hubo grandes marinos en el siglo XVII que conocían la estrategia militar y su aplicación al combate naval; sin embargo, las innovaciones de ingeniería naval para contrarrestar las inclemencias meteorológicas se convirtieron en la mejor de las estrategias, pues así lo exigían experiencias como la batalla de Gravelines en 1588, donde un importante número de galeazas españolas se hundieron o se perdieron a consecuencia del alto oleaje ${ }^{79}$. El marino español Alonso de Chávez lo ilustra con sus célebres palabras:

\footnotetext{
Se dice que todo intento de orden en el mar es infructuoso, pues ningún orden puede mantenerse. A esto respondo que, a igualdad de armamento, vencerá la flota mejor dispuesta, pues si ya la mar confunde a una flota ordenada, tanto más lo hará con la que no guarde el buen orden. ${ }^{80}$
}

Las bajas en las batallas navales eran un problema, y la preocupación por los efectivos dispuestos se observa en el discurso de Juan Bautista de Tassis con respecto al frente de

\footnotetext{
${ }^{75}$ Brownlee, Walter, La primera vuelta al mundo. Madrid, Akal, 1991, p. 24.

${ }^{76}$ Ibidem.

${ }^{77}$ Ibídem.

${ }^{78}$ Maura García, Francisco de Asís, La ingeniería naval... op. cit., p. 34.

${ }^{79}$ Ibidem, p. 35.

${ }^{80}$ Jörgensen, Christer, Técnicas bélicas del mundo moderno 1500-1763, Madrid, Libsa, 2007, p. 212.
} 
Dunquerque (1601) recogido por Martin \& Parker ${ }^{81}$ : "Si nosotros presentamos 100 barcos ellos presentan 400, y si más presentamos nosotros, más presentan ellos; y nunca tienen el más mínimo inconveniente en perder diez de sus navíos con tal de hundir uno de los nuestros" $\$ 2$.

El destino de las batallas solo se decidía de manera unívoca cuando la superioridad en naves y cañones por una de las partes era amplia y clara. De aplicar táctica se requería mantener la posición rigurosamente en la formación, un acertado y conocido código de señales y un alto grado de disciplina en las maniobras. No obstante, no llegará con precisión hasta finales del siglo XVII cuando se intenten las primeras formulaciones teóricas de la táctica de combate naval a través de la obra de Paul Hoste L'Art des armées navales de 1697; y la precedente inglesa Las instrucciones para el combate de $1691^{83}$.

La dificultad de la táctica aplicada al combate naval hace referencia a una visión de conjunto, es decir, batallas con un gran número de naves implicadas. Pero, en lo que respecta al combate de tú a tú entre naves de guerra, se conoce sobradamente el procedimiento. Precisamente García de Palacio ya lo narra a finales del siglo XVI con todo detalle en sus apartados "De la Nao que acomete" y "De la Nao que se defiende". Generalmente el capitán valora las posibilidades de abordaje y procura llevar la iniciativa buscando una posición favorable respecto al viento y la embarcación enemiga. Se arma y organiza a la tripulación y una vez establecida la posición deseada por el piloto, se abre fuego de artillería y se procede al abordaje:

\footnotetext{
Y para tener victoria procurará el piloto de coger y ganar siempre el barlovento, y barloar su nao perlongada con la del enemigo que busca. Proa con proa, y de esta y de la popa se echarán dos arpones para que las naos estén juntas y la gente al saltar no caiga en el mar. ${ }^{84}$
}

En paralelo los infantes de marina y la artillería ligera intentan diezmar la tripulación enemiga durante la acometida: “[...] y mientras todo esto sucediere, el batallón que defiende la nao ha de estar tirando siempre con verlos y mosquetes y arcabuces una tempestad continua de balas" $"$. En lo que respecta a la nave que se defiende, el capitán debe organizar la tripulación a tal fin; ha de mandar una escuadra el contramaestre que deberá acudir en socorro allá donde se le requiera. Cuando la embarcación enemiga llegue abarloando, se procurará colocar la embarcación para recibirla por la banda más conveniente.

Y cuando hubieren echado los arpones, ya que no se puede aprovechar a los arcabuces, la gente de pelea (De guerra), tomará picas y medias picas para defender su nao, y los lombarderos después de que hayan jugado su artillería

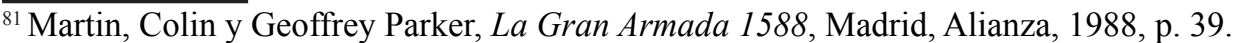

${ }^{82}$ Discurso del estado de guerra de Flandes de Juan Bautista de Tassis (1601), Dunquerque, cit. en Quintero, José, La importancia de Flandes en el rumbo del imperio y el papel de la flota en el conflicto, trabajo fin de máster, Universidad de Cádiz, 2017, p. 11.

${ }^{83}$ Casado Soto, José Luis, "Barcos para la guerra... op. cit., p. 39.

${ }^{84}$ García de Palacio, Diego, Instrucción náutica ... op cit., p. 125.

${ }^{85}$ Ibídem.
} 
tomaran sus bombas, alcancías e instrumentos de fuego y por las saeteras las tiraran y arrojaran a los contrarios: y si saltasen sobre la jareta falsa, batirán los puntales y después mataran y herirán los que cayeren con ella desde la jareta fija $[\ldots]{ }^{86}$

En ambos casos no cesaba el rugir del tambor, el pífano y las trompetas, no tanto para animar a las almas propias como para amedrantar a las contrarias, pues en este tipo de enfrentamientos de escasa duración, pero de gran violencia y en un reducido espacio físico, el factor psicológico debía ser determinante. "Y habiendo algún muerto, es menester echarlo debajo de la cubierta con brevedad, porque no sea visto, y el herido que lo lleven al cirujano, como queda dicho, para que después de curados, si pudieren vuelvan a la batalla"87.

No será hasta el siglo XVI cuando la guerra en el mar pase a ser el escenario en el que se ganan o se pierden coronas, surgiendo entonces la voluntad de armar las nuevas naves con la última tecnología artillera, asegurándose así la mayor capacidad ofensiva. Se generaliza la fundición en bronce de piezas de un solo bloque y se instalan flamantes cañones a bordo, modernizando la guerra en el mar. Además, dará comienzo un complejo proceso de adaptación de aquella artillería empleada en tierra, así como la creación de piezas diseñadas específicamente para su aplicación naval. Para la eficacia y maniobrabilidad de este nuevo concepto, fue indispensable la incorporación de la cureña, un soporte con ruedas o correderas sobre el cual descansa el cañón apoyando sus muñones en las gualderas de madera ${ }^{88}$.

En los siglos XVI y XVII las naves podían estar dotadas con piezas de largo, medio y corto alcance, así como fijas o portátiles ${ }^{89}$, pero aún no existía una clara estandarización de la artillería naval, conociendo apenas algunas categorías generales que nos aproximan al variado repertorio del momento. Si hablamos de artillería ligera, las versiones modernas de falconetes y pedreros apenas modificaron su morfología hasta el siglo XVIII. Eran ligeros, de pequeño tamaño e ideales para batir las cubiertas de los barcos enemigos en momentos previos al abordaje, por lo que se consideraban como armas anti-infantería $a^{90}$. Dentro de lo que se entiende como artillería liviana, se encuentran también ribadoquines, versos, sacabuches y carronadas, categorías determinadas por su peso y calibre.

Por otro lado, en lo que a artillería pesada se refiere, en tiempos de Felipe II se elabora una catalogación para facilitar la distribución óptima de las piezas a bordo. Se denomina culebrinas de manera general a todos los cañones pesados, subdivididos a su vez por calibres y pesos de los que resultan 4 categorías: doble culebrina, la más grande de todas con capacidad para disparar balas de 32 libras; media culebrina, capacitada para salvas de hierro de doce libras; el sacre,

\footnotetext{
${ }^{86}$ Ibídem, p. 128.

${ }^{87}$ Ibídem.

${ }^{88}$ Maura García, Francisco de Asís, La ingeniería naval... op. cit., p. 20.

${ }^{89}$ Pi Corrales, Magdalena de Pazzis, "La armada de ... op. cit., p. 29.

${ }^{90}$ Maura García, Francisco de Asís, La ingeniería naval... op cit., pp. 20-21.
} 
que disparaba balas de ocho libras; y el falconete, apto para disparar hasta seis libras ${ }^{91}$. En la primera mitad del siglo XVII, la Monarquía Hispánica empieza a producir en las fundiciones de Liérganes la popular artillería de hierro colado hasta entonces importada de Inglaterra. Se lograron importantes avances respecto a nuevos cañones e innovadoras municiones como los "ángeles enramados o encadenados", cuyas dos balas de hierro unidas a través de una cadena, destrozaban los palos de la mesana o los palos maestros de naves enemigas ${ }^{92}$.

La innovación conceptual en la elaboración de armas de guerra estaba sometida a un ritmo frenético, pues como indica Magdalena de Pazzis Pi Corrales, entre 1639 y 1669 la artillería de la marina de guerra evoluciona más que en los 50 años precedentes ${ }^{93}$. La incorporación de más cantidad de artillería a bordo puso sobre la mesa la disyuntiva: potencia de fuego frente maniobrabilidad y seguridad. La preocupación latente acerca del riesgo de la artillería a bordo se puede apreciar en las palabras de García de Palacio, quien lanza una temprana advertencia con respecto a las "matahombres" refiriéndose a piezas de artillería de fabricación pobre o instalación errada:

La artillería que se ha usado es de diversas formas, pero diré lo que me parece más conveniente para el uso de nuestra nao: piezas ay cerradas de bronce é hierro, y otras abiertas; de las de hierro sólo a mi parecer se deben usar algunas coladas, que teniendo con ellas cuidado aprovechen, y son seguras, todas las demás son matahombres, y pudiendo haber otras, aún no derivan usarse éstas: las de bronce son así las cerradas como las abiertas, que tienen cámaras buenas cada una para sus efectos: y así convendrá que sean fornidas de metal, y más cortas de lo ordinario, y que como ahora se usan, fenezca la culata en forma piramidal, aguda donde ha de dar y cebar el fogón, porque siendo tales se mandan y menean mejor, ocupan menos lugar, y no se calientan tan presto, y no hacen mucha fuerza al retirar $[\ldots] .^{94}$

Lo cierto es que los cañones eran armas letales que causaban enormes daños al enemigo, pero también muertes propias como consecuencia de las habituales explosiones accidentales. No obstante, las discusiones técnicas en conflictos bélicos suelen pecar de resultadistas, pues la opinión se inclinaba hacia un lado u otro en función del resultado de la batalla. Indudablemente la artillería a bordo tuvo éxito militar, pues ocasionó la revolución de la guerra naval, repercutiendo en múltiples modificaciones constructivas orientadas tanto a incrementar número de cañones como a resistir el fuego enemigo.

\footnotetext{
${ }^{91}$ Ibídem, p. 22.

${ }^{92}$ Ibídem, p. 23.

${ }^{93}$ Pi Corrales, Magdalena de Pazzis, "La armada de... op. cit., p. 30.

${ }^{94}$ García de Palacio, Diego, Instrucción náutica ... op cit., pp. 121-122.
} 


\section{Conclusiones}

En resumen, la expansión transoceánica alzó a los reinos ibéricos a una hegemonía naval sin parangón ${ }^{95}$ desde finales del siglo XV hasta la segunda mitad del siglo XVII, cuando el tablero se abrió hacia una competencia más concurrida entre el resto de las potencias europeas. En el presente artículo se han tenido en cuenta los trabajos de grandes historiadores especializados en este ámbito y se han podido constatar un buen número de ciclos intermitentes marcados por cotas de máxima producción naval e intervalos de estancamiento; fluctuación que generó notables deficiencias en la compleja maquinaria imperial. Tanto Carlos I como Felipe II aplicaron importantes medidas de contención, como la protección de la materia prima o la unificación sin éxito de la construcción naval; pero, a pesar de alcanzar logros significativos, el desafío que supuso la multifocalidad defensiva ${ }^{96}$ con escenarios tan diferentes como el Mediterráneo, la expansión ultramarina y el Mar del Norte, lo que hizo aún más difícil la articulación de acciones efectivas en todos los frentes.

Desde la victoria de Lepanto (1571) parece comenzar un periodo de optimismo estructural en lo que a la náutica se refiere, acrecentado nueve años más tarde con la unión de coronas, mediante la cual se incorpora la armada real portuguesa de los galeones del Índico ${ }^{97}$ y se accede a los recursos forestales lusos con las "coutadas y matas". Estos beneficios no vinieron solos, sino con la necesidad de proteger mucho más territorio costero perteneciente a Portugal y sus colonias, así como las rutas marítimas que las unían. Esta nueva organización territorial, junto a los múltiples frentes abiertos al norte, redujo la efectividad naval hispánica e hizo tambalear las arcas reales, entorpeciendo el mantenimiento del flujo de nuevos buques de transporte con tropas para Flandes, donde la participación naval fue ininterrumpida durante décadas ${ }^{98}$. Se promulgaron leyes que libraron de la presión fiscal a las atarazanas y se planificaron repoblaciones extensas de árboles para evitar la escasez de madera. Sin embargo, con la quiebra amenazante llegó la derrota de la armada invencible en 1588, evidenciando la pérdida de la hegemonía naval hispánica, al tiempo que holandeses y británicos progresaban aceleradamente.

Pese a la plena consciencia por parte de Felipe II sobre la importancia de mantener superioridad naval en el Mar del Norte para garantizar las posesiones flamencas, resultó imposible evitar la vulnerabilidad marítima de estos territorios, aun habiendo aplicado diversas estrategias de choque como la creación de las grandes armadas del Duque de Medinaceli y Pedro Menéndez de Avilés ${ }^{99}$.

\footnotetext{
${ }^{95}$ Pi Corrales, Magdalena de Pazzis, "La armada de... op. cit., p. 40.

${ }^{96}$ Caballos, Esteban Mira, Las Armadas Imperiales... op. cit., pp. 67-68.

${ }^{97}$ Ibídem, p. 30.

${ }^{98}$ Martin, Colin y Geoffrey Parker, La Gran Armada ... op. cit.

${ }^{99} \mathrm{Pi}$ Corrales, Magdalena de Pazzis, "Pedro de Valdés y la Armada de Flandes (1575)", en Cuadernos de historia moderna, 9 (1988), pp. 35-36.
} 
Llegados al reinado de Felipe III estos problemas se acentuaron, pues no recibe el esplendor naval otrora ostentado por su padre, sino una realidad desoladora habiendo perdido ritmo frente al galopante progreso de sus principales rivales. Esta pérdida de iniciativa, sumada a la escasez de madera que se viene arrastrando desde tiempos de Carlos I, generó deficiencias que perjudicaron el remplazo de naves en las múltiples diligencias del imperio, diezmando sustancialmente su salud, dado que la propia esencia de este exige el mantenimiento de un poder naval incontestable que garantice la conexión entre los vastos territorios que lo componen.

Felipe III estableció líneas prioritarias: la innovación tecnológica, un eficaz plan forestal y una eficiente estandarización de la construcción, pero fue la nueva política naval orquestada por el Conde Duque de Olivares durante el reinado de Felipe IV la que logró mantener el pulso en los mares y océanos del orbe. Sin embargo, el aumento de los frentes abiertos a causa de la guerra de los treinta años desangró la financiación destinada a la fuerza naval, situación recrudecida aún más con las revueltas provinciales en Cataluña, Nápoles y Palermo, así como la emancipación de Portugal en 1640.

Pese a todos los problemas analizados, lo cierto es que la frenética actividad de los astilleros españoles y las constantes innovaciones navales no se corresponden con la hipotética gran decadencia naval española en favor de las potencias concurrentes. Sin duda, ha quedado constatado que se trató de un sistema naval irregular y con altas dosis de improvisación que provocó a finales de siglo una considerable desaceleración, abriendo la puerta a la transición hegemónica. Pero, ciertamente, no sería justo omitir su asombrosa versatilidad ante un panorama defensivo tan complejo, en cuyo desempeño multipolar frente al extendido corsarismo y la creciente beligerancia de enemigos cada vez más duchos en estas lides se obtuvo un notable éxito, conservando al final de la centuria la mayor parte de las posesiones de ultramar.

Por último, señalar la importancia de una mirada desde el mar a las sociedades del pasado, pues sus lazos con este medio fueron, a todas luces, mayores y más fuertes que los actuales. Analizar la incuestionable influencia del mar en esta etapa histórica resulta, en mi opinión, imprescindible para su comprensión e interpretación, así como para el análisis de los efectos tecnológicos, económicos y sociales que sin duda acontecieron. Para ello, debe ser prioritaria la cooperación futura entre las disciplinas y subdisciplinas con capacidad de análisis en este ámbito, de manera que se logre una aproximación desde diferentes enfoques con intención de alcanzar un conocimiento holístico de nuestra historia. 